\title{
Assessment of hospital length of stay and direct costs of type 2 diabetes in Hubei Province, China
}

\author{
Dajie Chen ${ }^{\dagger}$, Shuai Liu ${ }^{\dagger}$, Xiaodong $\operatorname{Tan}^{*}$ (ID) and Qihan Zhao
}

\begin{abstract}
Background: The incidence of type 2 diabetes is increasing, creating a huge burden for China's social healthcare system. This study aimed to evaluate hospital length of stay (LOS) based on admission characteristics and direct costs correlated with various types of complications for type 2 diabetic inpatients in Hubei Province, China.
\end{abstract}

Methods: A total of 1528 inpatients diagnosed with type 2 diabetes discharged between April 1, 2013, and March 31, 2014, were included in this study. Information regarding patients' admission and hospitalization were obtained from the hospital information system. The relationship between admission characteristics and LOS, distribution of total costs, and types of complications were described and analysed.

Results: (1) The mean LOS was 11.65 days (median: 10 days). Multiple linear regression analysis demonstrated that inpatients with New Cooperative Medical Scheme (NCMS), aged 80 and above, had longer LOS than the reference group, and inpatients with chronic or acute + chronic complications had shorter LOS than those without. (2) Mean total costs per patient were US\$159.72 \pm 130.83 (median: US\$135.33), US\$240.60 \pm 166.58 (median: US\$192.09), and US\$247.98 \pm 166.22 (median: US\$200.99) for inpatients with no complications, chronic complications, and acute + chronic complications, respectively. Total and individual costs were significantly less for patients without complications than for those with the two types of complications $(p<0.001)$. (3) Mean total costs per patient were US\$225.40 \pm 115.32 (median: US\$200.34), US\$221.25 \pm 177.64 (median: US\$170.05), and US\$275.18 \pm 193.14 (median: US\$217.91) for inpatients with microvascular complications, macrovascular complications, and microvascular + macrovascular complications, respectively. Total costs were significantly higher for patients with microvascular + macrovascular complications than for those with other types of chronic complications $(p<0.001)$. (4) Drugs were the greatest expense for patients, and the least expensive treatment was nursing care.

Conclusions: Medical insurance status, age, and type of complication may help to predict LOS for patients with type 2 diabetes in Hubei Province, China. The total and individual costs for patients with complications were higher than for those without, and hospitalization expenses posed a heavy burden. Efforts should be made to reduce the financial impact on patients by integrating the medical insurance system of urban and rural areas, and by reducing the risk of complications, especially microvascular complications.

Keywords: Type 2 diabetes mellitus, Length of stay, Direct costs, Admission characteristics, Complications

\footnotetext{
* Correspondence: 723906547@qq.com

Dajie Chen and Shuai Liu are co-equal first author.

${ }^{\dagger}$ Equal contributors

Wuhan University, 115\# Donghu Road, Wuhan 430071, China
} 


\section{Background}

With global industrialization, urbanization, and modernization, the number of people afflicted with type 2 diabetes is growing year by year, with a projected increase from current estimates of 240 million, 6\% of adults, affected to some 380 million, or $7 \%$ of adults, by 2025 [1]. In developing countries, a low level of health literacy and rapid economic growth are expected to continue to lead to higher prevalence of the disease. According to data from the International Diabetes Federation, between 2010 and 2030, there will be a 69\% increase in numbers of adults with diabetes in developing countries, with $36 \%$ of the anticipated total global increase of 154 million people with diabetes projected to occur in India and China alone [2].

In recent years, huge changes have been taking place in Chinese society in terms of lifestyle and diet $[3,4]$. Increase in physical inactivity, unhealthy eating habits, obesity, and smoking have led to widespread incidence of diabetes $[5,6]$. According to an epidemiological study of diabetes in China, the age-standardized prevalence of total diabetes and prediabetes were 9.7 and 15.5\%, respectively, accounting for 92.4 million adults with diabetes and 148.2 million adults with prediabetes [7].

In China, the treatment of patients with diabetes has created significant problems for the social healthcare system. A systematic review of the direct economic burden of type 2 diabetes in China showed that the direct medical cost increased from US\$250 million in 1993 to US\$8.65 billion in 2008. The annual total inpatient cost increased from US\$30 million in 1993 to US\$3.13 billion in 2007, with an average annual growth rate of $19.90 \%$, which was more than the average annual growth rate of the gross domestic product (GDP (12.77\%) and national health expenditures (12.88\%) from 1993 to 2003 [8].

Inpatient costs were a substantial portion of health expenditures and were comprised of both direct and indirect costs; direct costs included cost of diagnosis and treatment of diabetes and its complications, and indirect costs represented productive losses resulting from prolonged length of stay (LOS), temporary or permanent disability, and premature death. This has been the subject of much research globally, but few studies have been carried out in Hubei Province, China. Therefore, assessing diabetic inpatients' LOS and hospitalization expenses to reflect the patients' burden was both necessary and urgent. This study aimed to estimate the LOS and direct costs of inpatients by analysing data on admission characteristics and a variety of complications and provide some suggestions for reducing the financial burden associated with type 2 diabetes.

A number of previous studies of LOS and direct costs of type 2 diabetes and its complications have been made $[9,10]$. However, they failed to relate to the content of these two aspects simultaneously $[11,12]$ and offered little analysis of direct costs with regard to the various types of complications in type 2 diabetes. The most prominent feature of this study was that the information of direct costs was explored from the perspectives of no complications, chronic complications (microvascular complications, macrovascular complications, and microvascular + macrovascular complications), acute complications, and acute + chronic complications.

\section{Methods}

\section{Data source and sample inclusion/exclusion criteria}

The study was carried out in Zhongnan Hospital, a large tertiary general hospital located in the capital of Hubei Province, China. Data on inpatients between April 1, 2013, and March 31, 2014, whose principal discharge diagnosis was type 2 diabetes were obtained from the hospital information system (HIS), with diagnosis of type 2 diabetes determined in accordance with World Health Organization guidelines [13]. Criteria for inclusion in this study were the following: (1) both the main discharge diagnosis and secondary diagnosis were type 2 diabetes or its complications, or the main discharge diagnosis ICD-10 coding was E11; (2) age $\geq 18$ years. Exclusion criteria were the following: (1) gestational diabetes; (2) neonatal diabetes; (3) transfer treatment; (4) deficits with primary data; (5) non-diabetic complications such as malignant tumours, fractures, and gastric ulcers. For inpatients undergoing two or more hospitalizations, each hospitalization was studied as a separate case, with our research focused on diabetic cases. The analysis ultimately consisted of 1528 cases.

\section{Data collection, study parameters, and definitions}

Inpatients' medical record information was exported to Microsoft Excel from the HIS (Additional file 1) and included (1) basic information such as hospitalization number, medical record number, type of medical insurance, name, gender, age, occupation, method of admission, admission time, discharge time, LOS, admission diagnosis, main discharge diagnosis, and other discharge diagnosis; (2) cost information for drugs, accommodation, imaging, therapeutics, laboratory analysis, sanitary materials, diagnostics, and nursing care. Information in Excel was preliminarily selected according to the inclusion and exclusion criteria and the above-mentioned information was preserved. Setting the year 2013 as the standard, the hospitalization costs were adjusted using China's consumer price index in order to take into account the influence of inflation on health care costs. Inpatients were classified into four groups according to the type of complications: no complications, chronic complications, acute complications, and acute + chronic complications. Chronic complications were further subdivided 
into three categories: microvascular complications, macrovascular complications, and microvascular + macrovascular complications. Diabetes related complications included in the analysis were identified based on the ICD-10 codes of complications [14] and classified as either (1) acute, including coma with or without ketoacidosis, hyperosmolar coma, hypoglycaemic coma, hyperglycaemic coma, acidosis, and ketoacidosis (http:// apps.who.int/classifications/icd10/browse/2010/en\#/E10E14), or (2) chronic, including macrovascular complications (acute myocardial infarction, angina pectoris, stroke, and non-traumatic amputation and foot ulcers) and microvascular complications (various levels of nephropathy [i.e., microalbuminuria, clinical proteinuria and chronic renal failure], retinopathy [i.e., background and proliferative retinopathy, macular edema, cataracts, and blindness], and peripheral neuropathy [11]).

\section{Statistical analysis}

Numeric variables were reported as Mean \pm standard deviation (SD), Median/25th-75th percentile, and categorical variables were described as both numbers and percentages.

Because LOS and hospitalization costs did not conform to the normal distribution, the Mann-Whitney $U$ test (with 2 subgroups) and Kruskal-Wallis test (with multiple subgroups) were used for a preliminary exploration of factors associated with LOS in univariate analysis and to evaluate the distributions of hospitalization costs between subgroups. Multiple linear regression was used to select variables which significantly predicted LOS. To avoid overfitting the model, variables found to be significant ( $p<0.10$, inclusion criteria) in the univariate analysis were included.

Data filtering was performed using Excel and analyses were carried out using IBM SPSS Statistics 20. $P<0.05$ was considered to be statistically significant.

\section{Results}

\section{Demographic, clinic characteristics of the study population}

A total of 1528 patients were included in the study. Of them, 944 were men $(61.78 \%)$, with a mean age of 61.78 years (median: 60 years), and mean LOS of 11.65 days (median: 10 days). Urban Employee Basic Medical Insurance, Urban Resident Basic Medical Insurance, and the NCMS covered $44.82 \%(n=685)$ of patients, and $96.20 \%(n=1470)$ patients were admitted as outpatients. Most of the patients were retired (47.19\%). Data from Table 1 shows that most inpatients (81.74\%) had chronic complications (Table 1).

\section{Univariate analysis result}

The Mann-Whitney $U$ test (with 2 subgroups) and Kruskal-Wallis test (with multiple subgroups) showed that no significant difference was found between LOS and gender $(p=0.056)$, mode of admission $(p=0.057)$, or year of admission $(p=0.998)$. Age group, type of medical insurance, occupation, and type of complications $(p<0.001)$ were significantly associated with LOS. Inpatients aged 90 and over, receiving public financial assistance, retired, and without complications had a longer LOS than other members within the group, their mean LOS were 19.94 \pm 5.96 days, $14.19 \pm 6.11$ days, $12.54 \pm 6.29$ days, $15.43 \pm$ 7.17 days, respectively (Table 2 ).

\section{Multiple linear regression analysis}

Age group, type of medical insurance, occupation, and type of complications which were found to be statistically significant in the univariate analysis were predictors, and the LOS was the outcome variable for analysis. According to the multiple linear regression analysis of LOS, it could be concluded that age group, type of medical insurance, and complications were the factors associated with LOS. Inpatients with NCMS had a longer LOS than with Urban Resident Basic Medical Insurance. Compared with inpatients aged 20-30 years, those aged 80-90 had a longer LOS. Moreover, inpatients aged 90 and over had the longest LOS. A significant difference was found between LOS and complications as well. Compared to inpatients without complications, inpatients with chronic complications and with acute + chronic complications had longer LOS (Table 3).

\section{Cost differencess between various complications}

The mean cost per patient was US\$232.47, and the total costs were US $\$ 159.72 \pm 130.83$, US $\$ 240.60 \pm 166.58$, and US\$247.98 \pm 166.22 for inpatients with no complications, chronic complications, and acute + chronic complications, respectively, as shown in Table 4 . The distribution of costs for total expenses, drugs, accommodation, imaging, laboratory analysis, diagnostics, and nursing care were significantly different not only between inpatients without complications and those with chronic complications but also between inpatients without complications and those with acute + chronic complications $(p<0.001)$. The distribution of costs for therapeutics and sanitary materials were significantly different between the three different types of complications $(p<0.001)$. We can conclude inpatients without complications spent less than those with other types of complications on total costs and on the various individual expenses. Drugs and laboratory analysis were found to be the greatest expenses, and the least was nursing care (Table 4).

\section{Cost differences between various chronic complications}

Chronic complications in type 2 diabetes patients was divided into three categories: microvascular, macrovascular, and microvascular + macrovascular complications 
Table 1 Demographic and clinical characteristics of the study population

\begin{tabular}{|c|c|c|c|c|}
\hline Characteristics & & Mean \pm SD or number & Median or percentage & 25th-75th percentile \\
\hline \multirow[t]{2}{*}{ Gender } & Male & 944 & 61.78 & \\
\hline & Female & 584 & 38.22 & \\
\hline \multirow[t]{8}{*}{ Age group } & $20 \sim$ & 16 & 1.05 & \\
\hline & $30 \sim$ & 53 & 3.47 & \\
\hline & $40 \sim$ & 303 & 19.83 & \\
\hline & $50 \sim$ & 365 & 23.89 & \\
\hline & $60 \sim$ & 268 & 17.54 & \\
\hline & $70 \sim$ & 287 & 18.78 & \\
\hline & $80 \sim$ & 218 & 14.27 & \\
\hline & $90 \sim$ & 18 & 1.18 & \\
\hline LOS & & $11.65 \pm 6.13$ & 10 & $8-15$ \\
\hline \multirow[t]{6}{*}{ Type of medical insurance } & Urban Resident Basic Medical Insurance & 41 & 2.68 & \\
\hline & Urban Employee Basic Medical Insurance & 603 & 39.46 & \\
\hline & Other means of payment & 23 & 1.51 & \\
\hline & Public expense & 31 & 2.03 & \\
\hline & Private expense & 789 & 51.64 & \\
\hline & NCMS & 41 & 2.68 & \\
\hline \multirow[t]{3}{*}{ Mode of Admission } & Emergency & 29 & 1.90 & \\
\hline & Outpatient & 1470 & 96.20 & \\
\hline & Other & 29 & 1.90 & \\
\hline \multirow[t]{2}{*}{ Year of admission } & 2013 & 724 & 47.38 & \\
\hline & 2014 & 804 & 52.62 & \\
\hline \multirow[t]{5}{*}{ Occupation } & Employee & 248 & 16.23 & \\
\hline & Student & 3 & 0.20 & \\
\hline & Labourer & 181 & 11.84 & \\
\hline & Retired & 721 & 47.19 & \\
\hline & Unemployed & 375 & 24.54 & \\
\hline \multirow[t]{3}{*}{ Complications } & No complications & 164 & 10.73 & \\
\hline & Chronic complications & 1249 & 81.74 & \\
\hline & Acute + chronic complications & 115 & 7.53 & \\
\hline Costs per patient & & $232.47 \pm 164.95$ & 185.00 & $142.04-272.18$ \\
\hline
\end{tabular}

as shown in Table 5. The total costs were US $\$ 225.40 \pm$ 115.32, US $\$ 221.25 \pm 177.64$, and US $\$ 275.18 \pm 193.14$, respectively. The distribution of total costs and accommodation costs were significantly different between the three categories $(p<0.001)$. The distribution of costs for therapeutics and nursing care were significantly different not only between inpatients with microvascular complications and with microvascular + macrovascular complications but also between inpatients with macrovascular complications and with microvascular + macrovascular complications $(p<0.001)$. The distribution of costs for drugs, imaging, laboratory analysis, sanitary materials, and diagnostics showed significant differences between inpatients with macrovascular complications and with microvascular complications as well as between inpatients with macrovascular complications and with microvascular + macrovascular complications $(p<0.001)$. From the perspective of the total costs, inpatients with microvascular + macrovascular complications spent the most. Drugs and laboratory analysis were the highest costs and nursing care was the lowest (Table 5).

\section{Discussion}

LOS and demographic and clinical characteristics

Through this study, Wuhan, a medium-sized city in China where LOS of inpatients with diabetes (means: $11.65 \pm 6.13$ days; median: 10.00 days) were slightly shorter than those reported in Shantou, China (means: 
Table 2 Factors associated with LOS by univariate analysis

\begin{tabular}{|c|c|c|c|c|}
\hline Factors & & Mean days & Median days & $P$-value \\
\hline \multirow[t]{2}{*}{ Gender } & Male & $11.40 \pm 6.04$ & $10.00(7.00-14.00)$ & 0.056 \\
\hline & Female & $12.04 \pm 6.27$ & $11.00(8.00-15.00)$ & \\
\hline \multirow[t]{8}{*}{ Age group } & $20 \sim$ & $9.06 \pm 3.79$ & $9.00(6.00-12.75)$ & $<0.001$ \\
\hline & $30 \sim$ & $10.00 \pm 5.63$ & $9.00(7.00-10.50)$ & \\
\hline & $40 \sim$ & $10.95 \pm 6.21$ & $10.00(7.00-13.00)$ & \\
\hline & $50 \sim$ & $9.83 \pm 5.09$ & $9.00(7.00-13.00)$ & \\
\hline & $60 \sim$ & $10.71 \pm 5.12$ & $10.00(8.00-13.00)$ & \\
\hline & $70 \sim$ & $12.45 \pm 5.99$ & $11.00(9.00-15.00)$ & \\
\hline & $80 \sim$ & $15.67 \pm 6.73$ & $16.00(11.00-21.00)$ & \\
\hline & $90 \sim$ & $19.94 \pm 5.96$ & $21.00(16.75-23.25)$ & \\
\hline \multirow[t]{6}{*}{ Type of medical insurance } & Urban Resident Basic Medical Insurance & $10.31 \pm 5.39$ & $9.00(7.00-11.00)$ & $<0.001$ \\
\hline & Urban Employee Basic Medical Insurance & $10.14 \pm 4.84$ & $9.00(7.00-12.00)$ & \\
\hline & Other & $13.30 \pm 5.41$ & $13.00(11.00-17.00)$ & \\
\hline & Public expense & $14.19 \pm 6.11$ & $15.00(10.00-19.00)$ & \\
\hline & Private expense & $12.65 \pm 6.74$ & $12.00(8.00-17.00)$ & \\
\hline & NCMS & $12.95 \pm 7.15$ & $11.00(8.50-15.50)$ & \\
\hline \multirow[t]{5}{*}{ Occupation } & Employee & $10.95 \pm 6.20$ & $10.00(7.00-15.00)$ & $<0.001$ \\
\hline & Student & $12.00 \pm 5.57$ & $13.00(6.00-)$ & \\
\hline & Labourer & $10.32 \pm 5.26$ & $9.00(7.00-13.00)$ & \\
\hline & Employed & $12.54 \pm 6.29$ & $11.00(8.00-16.00)$ & \\
\hline & Unemployed & $11.02 \pm 5.94$ & $10.00(8.00-13.00)$ & \\
\hline \multirow[t]{3}{*}{ Mode of Admission } & Emergency & $10.62 \pm 7.81$ & $9.00(4.50-13.00)$ & 0.057 \\
\hline & Outpatient & $11.68 \pm 5.95$ & $10.00(8.00-15.00)$ & \\
\hline & Other & $11.03 \pm 11.33$ & $9.00(2.00-14.50)$ & \\
\hline \multirow[t]{2}{*}{ Year of admission } & 2013 & $11.67 \pm 6.31$ & $10.00(8.00-14.00)$ & 0.998 \\
\hline & 2014 & $11.62 \pm 5.97$ & $10.00(8.00-15.00)$ & \\
\hline \multirow[t]{3}{*}{ Complications } & No complications & $15.43 \pm 7.17$ & $15.50(10.00-22.00)$ & $<0.001$ \\
\hline & Chronic complications & $11.23 \pm 5.84$ & $10.00(8.00-14.00)$ & \\
\hline & Acute + chronic complications & $10.74 \pm 5.81$ & $10.00(7.00-13.00)$ & \\
\hline
\end{tabular}

13.91 days; median: 10.00 days) [15] but slightly longer than those found abroad (means: 8.2 days) [12]. These discrepancies may stem from the type and grade of hospital, the standard charges, the conditions for care, and the social and cultural environment $[16,17]$.

The findings of the multiple linear regression analysis were unlike much previous research $[18,19]$ in that people with the new cooperative medical scheme had a longer LOS than people with Urban Resident Basic Medical Insurance and with Urban Employee Basic Medical Insurance. Despite a relatively high coverage of medical insurance in China, the coverage provided by different types of social medical insurance in the country varies greatly. At present, Urban Employee Basic Medical Insurance, as an earlier developed and more mature social medical insurance in China, is superior to other social medical insurance plans in its coverage and cost in terms of deductible and rate of reimbursement. The difference mentioned above is the main reason why Urban Employee Basic Medical Insurance would increase the cost of hospitalization and the LOS. However, our study draws different conclusions, which can be explained as follows: Zhongnan Hospital, as a large tertiary general hospital, serves not only the immediate urban area but also the rural area which surrounds it. The current grading clinics allow patients living in rural areas, most of whom are enrolled in the new cooperative medical schemes, to come to Zhongnan Hospital for further treatment of more serious conditions. Thus, the results of this study showed that the LOS of patients with the new cooperative medical scheme were longer. From these results, we can conclude that establishing an 
Table 3 Factors associated with LOS by multiple linear regression analysis

\begin{tabular}{|c|c|c|c|c|c|c|}
\hline \multirow[t]{2}{*}{ Factors } & \multirow[t]{2}{*}{ Reference group } & \multirow[t]{2}{*}{ B } & \multirow[t]{2}{*}{ Std. Error } & \multicolumn{2}{|l|}{$95 \%$ C.I } & \multirow[t]{2}{*}{$P$-value } \\
\hline & & & & Lower & Upper & \\
\hline \multicolumn{7}{|l|}{ Gender } \\
\hline Female & Male & 0.165 & 0.319 & -0.459 & 0.790 & 0.604 \\
\hline \multicolumn{7}{|l|}{ Age group } \\
\hline $30 \sim$ & $20 \sim$ & 1.339 & 1.761 & -2.112 & 4.790 & 0.447 \\
\hline $40 \sim$ & & 2.091 & 1.612 & -1.069 & 5.252 & 0.195 \\
\hline $50 \sim$ & & 0.591 & 1.616 & -2.577 & 3.758 & 0.715 \\
\hline $60 \sim$ & & 1.325 & 1.642 & -1.893 & 4.543 & 0.420 \\
\hline $70 \sim$ & & 2.856 & 1.645 & -0.368 & 6.081 & 0.083 \\
\hline $80 \sim$ & & 5.161 & 1.671 & 1.887 & 8.435 & 0.002 \\
\hline $90 \sim$ & & 8.328 & 2.157 & 4.101 & 12.555 & 0.001 \\
\hline \multicolumn{7}{|l|}{ Type of medical insurance } \\
\hline Urban Employee Basic Medical Insurance & Urban Resident Basic Medical Insurance & -0.050 & 0.921 & -1.856 & 1.756 & 0.957 \\
\hline Other & & 2.541 & 1.486 & -0.372 & 5.454 & 0.087 \\
\hline Public expense & & 2.250 & 1.383 & -0.460 & 4.961 & 0.104 \\
\hline Private expense & & 1.489 & 0.919 & -0.311 & 3.290 & 0.105 \\
\hline NCMS & & 3.053 & 1.265 & 0.574 & 5.531 & 0.016 \\
\hline \multicolumn{7}{|l|}{ Occupation } \\
\hline Labourer & Employee & 0.118 & 0.577 & -1.014 & 1.249 & 0.839 \\
\hline Retired & & 0.843 & 0.483 & -0.104 & 1.790 & 0.081 \\
\hline Unemployed & & 0.506 & 0.471 & -0.416 & 1.429 & 0.282 \\
\hline \multicolumn{7}{|l|}{ Mode of Admission } \\
\hline Outpatient & Emergency & 1.331 & 1.079 & -0.784 & 3.445 & 0.217 \\
\hline Other & & 0.348 & 1.507 & -2.605 & 3.301 & 0.817 \\
\hline \multicolumn{7}{|l|}{ Complications } \\
\hline Chronic complications & No complications & -1.678 & 0.548 & -2.751 & -0.605 & 0.002 \\
\hline Acute + chronic complications & & -2.475 & 0.753 & -3.951 & -0.998 & 0.001 \\
\hline
\end{tabular}

The occupation "student" was not included in the multiple linear regression analysis because the sample size was limited to 3

Table 4 Hospitalization costs of type 2 diabetes in patients with various complications

\begin{tabular}{|c|c|c|c|c|c|c|c|}
\hline \multirow{2}{*}{$\begin{array}{l}\text { Hospitalization } \\
\text { costs }\end{array}$} & \multicolumn{2}{|c|}{ No complications } & \multicolumn{2}{|c|}{ Chronic complications } & \multicolumn{2}{|c|}{ Acute + chronic complications } & \multirow[t]{2}{*}{$P$-value } \\
\hline & Mean \pm SD & Median & Mean \pm SD & Median & Mean \pm SD & Median & \\
\hline Total costs & $159.72 \pm 130.83$ & 135.33 (92.03-184.28) & $240.60 \pm 166.58$ & $192.09(147.81-282.30)^{a}$ & $247.98 \pm 166.22$ & $200.99(155.47-286.39)^{b}$ & $<0.001$ \\
\hline Drugs & $68.69 \pm 75.18$ & $57.84(27.98-84.92)$ & $111.60 \pm 84.44$ & $89.60(61.67-138.62)^{a}$ & $115.59 \pm 82.89$ & $95.45(62.99-135.40)^{\mathrm{b}}$ & $<0.001$ \\
\hline Accommodation & $10.28 \pm 12.35$ & $7.71(4.24-12.95)$ & $14.90 \pm 19.19$ & $11.64(8.81-15.80)^{\mathrm{a}}$ & $13.28 \pm 6.99$ & $11.11(8.81-16.26)^{b}$ & $<0.001$ \\
\hline Imaging & $16.48 \pm 14.61$ & $15.03(4.98-23.06)$ & $25.65 \pm 19.87$ & $22.35(13.26-33.55)^{\mathrm{a}}$ & $23.93 \pm 17.13$ & $22.06(11.15-31.75)^{b}$ & $<0.001$ \\
\hline Therapeutics & $14.41 \pm 36.90$ & $6.63(2.32-11.38)$ & $27.12 \pm 48.69$ & $10.92(5.79-20.07)^{a}$ & $31.15 \pm 49.19$ & $13.84(8.48-24.89)^{\mathrm{bc}}$ & $<0.001$ \\
\hline Lab analysis & $32.85 \pm 22.34$ & $31.55(19.01-46.50)$ & $44.62 \pm 26.04$ & $39.72(28.33-56.05)^{\mathrm{a}}$ & $44.44 \pm 25.33$ & $38.76(25.68-58.61)^{b}$ & $<0.001$ \\
\hline $\begin{array}{l}\text { Sanitary } \\
\text { materials }\end{array}$ & $5.25 \pm 5.69$ & $3.78(1.84-6.81)$ & $11.48 \pm 62.34$ & $5.31(3.35-7.77)^{a}$ & $14.31 \pm 32.36$ & $6.54(4.31-9.76)^{\mathrm{bc}}$ & $<0.001$ \\
\hline Diagnostics & $1.55 \pm 1.08$ & $1.42(0.75-2.06)$ & $2.24 \pm 1.06$ & $2.06(1.53-2.68)^{\mathrm{a}}$ & $2.27 \pm 1.01$ & $2.07(1.53-2.87)^{b}$ & $<0.001$ \\
\hline Nursing care & $1.09 \pm 1.77$ & $0.76(0.47-1.32)$ & $1.65 \pm 1.45$ & $1.15(0.86-1.91)^{\mathrm{a}}$ & $1.82 \pm 1.55$ & $1.23(0.85-2.10)^{b}$ & $<0.001$ \\
\hline
\end{tabular}

A Dunn's nonparametric comparison for post hoc testing after a Kruskal-Wallis test were performed and indicated significant differences between groups of no complications and chronic complications, no complications and acute + chronic complications, and chronic complications and acute + chronic complications, as illustrated a, b, c respectively in Table 4 
Table 5 Hospitalization costs of type 2 diabetes in patients with various chronic complications

\begin{tabular}{|c|c|c|c|c|c|c|c|}
\hline \multirow{2}{*}{$\begin{array}{l}\text { Hospitalization } \\
\text { costs }\end{array}$} & \multicolumn{2}{|l|}{ Microvascular } & \multicolumn{2}{|l|}{ Macrovascular } & \multicolumn{2}{|c|}{ Microvascular + macrovascular } & \multirow[t]{2}{*}{$P$-value } \\
\hline & Mean \pm SD & Median & Mean \pm SD & Median & Mean \pm SD & Median & \\
\hline Total costs & $225.40 \pm 115.32$ & $200.34(151.00-263.24)$ & $221.25 \pm 177.64$ & $170.05(134.81-255.11)^{\mathrm{a}}$ & $275.18 \pm 193.14$ & $217.91(158.94-345.02)^{b c}$ & $<0.001$ \\
\hline Drugs & $109.11 \pm 67.82$ & $94.80(65.25-137.20)$ & $99.60 \pm 76.64$ & $80.26(57.07-119.78)^{a}$ & $125.87 \pm 103.22$ & $96.08(63.04-164.70)^{c}$ & $<0.001$ \\
\hline Accommodation & $13.12 \pm 7.55$ & $11.72(8.99-15.09)$ & $13.24 \pm 13.98$ & $10.11(7.71-15.42)^{\mathrm{a}}$ & $18.37 \pm 29.02$ & $12.38(9.91-17.73)^{b c}$ & $<0.001$ \\
\hline Imaging & $28.19 \pm 19.55$ & $24.26(15.97-35.40)$ & $21.84 \pm 16.31$ & $19.85(10.84-29.24)^{\mathrm{a}}$ & $26.74 \pm 22.65$ & $22.61(11.48-35.99)^{c}$ & $<0.001$ \\
\hline Therapeutics & $16.08 \pm 20.87$ & $10.76(5.71-16.61)$ & $29.55 \pm 54.91$ & $10.33(5.31-19.92)$ & $36.14 \pm 59.49$ & $11.71(6.47-29.3)^{b c}$ & 0.005 \\
\hline Lab analysis & $45.96 \pm 25.19$ & $40.30(28.55-58.62)$ & $40.44 \pm 19.78$ & $37.33(27.69-50.51)^{\mathrm{a}}$ & $47.30 \pm 31.32$ & $41.37(28.94-60.36)^{c}$ & 0.007 \\
\hline $\begin{array}{l}\text { Sanitary } \\
\text { materials }\end{array}$ & $7.14 \pm 10.02$ & $5.52(3.69-7.46)$ & $12.15 \pm 95.75$ & $4.64(2.84-7.01)^{\mathrm{a}}$ & $15.31 \pm 49.03$ & $6.02(3.59-9.15)^{c}$ & $<0.001$ \\
\hline Diagnostics & $2.22 \pm 0.95$ & $2.10(1.69-2.62)$ & $2.08 \pm 0.99$ & $1.87(1.50-2.62)^{\mathrm{a}}$ & $2.40 \pm 1.21$ & $2.25(1.69-2.87)^{c}$ & $<0.001$ \\
\hline Nursing care & $1.34 \pm 1.17$ & $1.12(0.85-1.42)$ & $1.55 \pm 1.36$ & $1.05(0.76-1.87)$ & $2.08 \pm 1.69$ & $1.63(0.96-2.62)^{b c}$ & $<0.001$ \\
\hline
\end{tabular}

A Dunn's nonparametric comparison for post hoc testing after a Kruskal-Wallis test were performed and indicated significant differences between groups of microvascular complications and macrovascular complications, microvascular complications and microvascular + macrovascular complications, and macrovascular complications and microvascular + macrovascular complications, as illustrated a, b, c respectively in Table 5

unified basic medical insurance system for urban and rural residents to guarantee basic medical insurance rights and interests, promote social fairness, and encourage urban-rural coordinated development is needed. China is currently exploring a new way to integrate the medical insurance system of urban and rural areas [20].

In addition, the multiple linear regression analysis showed another result different from many studies which indicated that people without complications had a longer LOS than people with chronic complications and acute + chronic complications [21-23]. The mean LOS were $11.23 \pm 5.84$ and $10.74 \pm 5.81$ days respectively for patients with chronic complications and acute + chronic complications as opposed to $15.43 \pm 7.17$ days for patients without complications. One possible reason for this is that most inpatients without complications were hospitalized for the first time, or this was the first time the disease had been diagnosed, so they paid more attention to the disease and accepted longer hospitalization in order to control the development of the disease. However, patients with complications may have been more likely to receive a shorter hospitalization and then maintain drug treatment at home.

\section{Costs and various type of complications}

The result of the study showed that the average per patient cost of diabetes was US $\$ 232.47$ and the median cost was US\$185.00. This is different from that found in some other parts of China and abroad [24, 25]. For instance, the average cost per patient was far less than that in Europe and the United Arab Emirates [11], but was slightly higher than the US\$152 per patient in Iran [26]. China is a developing country, with its own unique national conditions, medical and health service systems, hospital grades and settings, and these may be responsible for the discrepancy in average per patient cost. According to a survey of resident income in China, GDP per capita was US\$4410.59 (29,992 RMB, with an exchange rate for US\$ to RMB of 1:6.8 in 2010) [27]. The average hospitalization cost for diabetic patients was $5.27 \%$ of the GDP per capita and $55.35 \%$ of the per capital expenditure for health care (http://data.worldbank.org.cn/indicator/SH.XPD.PCAP/co untries). This means diabetes is a huge burden both for residents and for the health care system. Other studies have come to the same conclusion [28].

This study found that costs for inpatients with complications were higher than for patients without complications, and numerous studies have drawn similar conclusions $[29,30]$. This study also found total costs for patients with microvascular + macrovascular complications were higher than those for patients with microvascular complications alone. Moreover, this research showed that patients with macrovascular complications spent the least. These findings which were completely contrary to the conclusions of the study conducted in Europe and the United Arab Emirates, which found that patients with microvascular + macrovascular complications spend the most, followed by those with macrovascular complications, in that study, patients with microvascular complications spent the least [11]. As the disease progresses, a series of complications will inevitably occur, either with regard to personal health or in terms of the social economic burden, preventing and controlling the complications of diabetes, especially microvascular complications, are essential.

Regardless of the kind of complication, drugs were the highest type of cost and nursing care the least. Therefore, in order to reduce the burden of the disease in patients with type 2 diabetes, measures should be taken to reduce drug costs in conjunction with the implementation of drug price reform policies in Hubei Province. Moreover, because diabetes is a metabolic disease, in addition to access to affordable medication, health education and lifestyle interventions are also very important, as many studies have shown [31, 32]. In this way, both LOS and hospital costs would decrease. 


\section{Limitations}

Because this study was conducted with data from a single hospital, findings might have been different in other parts of the country or in other types of hospitals. In addition, the data was limited to the period between April 1, 2013, and March 31, 2014, a relatively short time span; thus, a continuous trend comparison could not be made. Also, for patients undergoing two or more hospitalizations, each hospitalization was studied as a separate case, which may have led to an underestimate of hospital costs. Moreover, some cardiovascular diseases are not limited to patients with diabetes but may occur before diabetes, so some of the costs might not have been caused by diabetes, leading to an overestimation of hospital costs. Finally, the data for demographic and clinic characteristics were limited (e.g., the results of laboratory tests), if more data for demographic and clinical characteristics had been available, this research would be more substantial.

\section{Conclusions}

The LOS for patients with diabetes in China were found to be longer than those in foreign countries. It should be appropriate to take measures, such as integrating the medical insurance system of urban and rural areas as well as monitoring and educating patients at home. Overall, the costs for patients with complications were higher than for patients without complications, so preventing and controlling the complications of diabetes is imperative, especially microvascular complications.

\section{Additional file}

Additional file 1: LOS and direct costs of type2 diabetes. Title of data: Sheet1 (LOS and direct costs of all type2 diabetes patients); Sheet2 (LOS and direct costs of type2 diabetes patients with chronic complications). Description of data: Basic information such as type of medical insurance, gender, age, occupation, method of admission, LOS, type of complications and cost information for drugs, accommodation, imaging, therapeutics, laboratory analysis, sanitary materials, diagnostics, and nursing care are included. (XLSX $540 \mathrm{~kb}$ )

\section{Abbreviations}

\$: US dollars; GDP: Gross Domestic Product; HIS: Hospital Information System; LOS: Length of stay; NCMS: New Cooperative Medical Scheme; RMB: Ren Min Bi; SD: Standard deviation

\section{Acknowledgements}

The authors thank all members in Professor XD Tan's team in Wuhan University for their valuable assistance.

\section{Funding}

No funding was obtained.

\section{Availability of data and materials}

The authors agree others to make freely available any materials and information described in their publication that may be reasonably requested.

\section{Authors' contributions}

DC and SL performed the literature search, study design, data analysis, and draft the manuscript. XD Tan contributed to revision of manuscript and QZ contributed to the literature search. All authors read and approved the final manuscript.

\section{Competing interests}

The authors declare that they have no competing interests.

\section{Consent for publication}

Not applicable

\section{Ethics approval and consent to participate}

Ethical approval was given by the medical ethics committee of School of Medicine, Wuhan University with the following reference number:7. When the patients admitted to hospital, they would give a consent to participate by understanding their data would be used for research in the future and administrative permission has been received from the hospital for this purpose.

\section{Publisher's Note}

Springer Nature remains neutral with regard to jurisdictional claims in published maps and institutional affiliations.

Received: 2 August 2016 Accepted: 7 March 2017

Published online: 14 March 2017

\section{References}

1. van Dieren S, Beulens JW, van der Schouw YT, Grobbee DE, Neal B. The global burden of diabetes and its complications: an emerging pandemic. Eur J Cardiovasc Prev Rehabil. 2010;17 Suppl 1:S3-8.

2. Shaw JE, Sicree RA, Zimmet PZ. Global estimates of the prevalence of diabetes for 2010 and 2030. Diabetes Res Clin Pract. 2010;87(1):4-14.

3. Campbell TC, Parpia B, Chen J. Diet, lifestyle, and the etiology of coronary artery disease: the Cornell China study. Am J Cardiol. 1998;82(10B):18T-21.

4. Wang $X$, Wu $Y$, Zhang $X$, Zhang M, Huang G. Dietary Changes over 25 Years in Tianjin Residents: Findings from the 1986-1988, 2000-2004, and 20082011 Nutrition Surveys. Nutrients. 2016;8(2):62.

5. Cong JY, Zhao Y, Xu QY, Zhong CD, Xing QL. Health-related quality of life among Tianjin Chinese patients with type 2 diabetes: a cross-sectional survey. Nurs Health Sci. 2012;14(4):528-34.

6. Xue H, Wang C, Li Y, Chen J, Yu L, Liu X, Li J, Cao J, Deng Y, Guo D, et al. Incidence of type 2 diabetes and number of events attributable to abdominal obesity in china: a cohort study. J Diabetes. 2016;8(2):190-8.

7. Yang WY, Lu JM, Weng JP, Jia WP, Ji LN, Xiao JZ, Shan ZY, Liu J, Tian HM, Ji $\mathrm{QH}$, et al. Prevalence of diabetes among men and women in China. New Engl J Med. 2010;362(12):1090-101.

8. Hu H, Sawhney M, Shi L, Duan S, Yu Y, Wu Z, Qiu G, Dong H. A systematic review of the direct economic burden of type 2 diabetes in china. Diabetes Ther. 2015;6(1):7-16.

9. Malone M, Lau NS, White J, Novak A, Xuan W, lliopoulos J, Crozier J, Dickson HG. The effect of diabetes mellitus on costs and length of stay in patients with peripheral arterial disease undergoing vascular surgery. Eur J Vasc Endovasc Surg. 2014:48(4):447-51.

10. Arredondo A, Aviles R. Healthcare costs in older adults with diabetes mellitus: challenges for health systems and for society. J Am Geriatr Soc. 2015;63(11):2421-3.

11. Al-Maskari F, El-Sadig M, Nagelkerke N. Assessment of the direct medical costs of diabetes mellitus and its complications in the United Arab Emirates. BMC Public Health. 2010;10:679.

12. Comino EJ, Harris MF, Islam MD, Tran DT, Jalaludin B, Jorm L, Flack J, Haas M. Impact of diabetes on hospital admission and length of stay among a general population aged 45 year or more: a record linkage study. BMC Health Serv Res. 2015;15:12.

13. Alberti KGMM, Zimmet PZ, Consultation W. Definition, diagnosis and classification of diabetes mellitus and its complications part 1: Diagnosis and classification of diabetes mellitus - Provisional report of a WHO consultation. Diabetic Med. 1998;15(7):539-53.

14. Lesniowska J, Schubert A, Wojna M, Skrzekowska-Baran I, Fedyna M. Costs of diabetes and its complications in Poland. Eur J Health Econ. 2014;15(6):653-60. 
15. Huang DJ, Xie LZ, Qiu Y. Analysis of factors affecting the length of hospital stay for patients with diabetes. Exp Clin Endocrinol Diabetes. 2016;124(1):5-10.

16. Kuo YF, Goodwin JS. Effect of hospitalists on length of stay in the medicare population: variation according to hospital and patient characteristics. J Am Geriatr Soc. 2010;58(9):1649-57.

17. Cheng JS, Tsai WC, Lin CL, Chen LW, Lang HC, Hsieh HM, Shin SJ, Chen T, Huang CT, Hsu CC. Trend and factors associated with healthcare use and costs in type 2 diabetes mellitus a decade experience of a universal health insurance program. Med Care. 2015;53(2):116-24.

18. Ma Y, Liu Y, Fu HM, Wang XM, Wu BH, Wang SX, Peng GG. Evaluation of admission characteristics, hospital length of stay and costs for cerebral infarction in a medium-sized city in China. Eur J Neurol. 2010;17(10):1270-6.

19. Bao X, Yang C, Fang K, Shi M, Yu G, Hu Y. Hospitalization costs and complications in hospitalized patients with type 2 diabetes mellitus in Beijing, China. J Diabetes. 2016. doi:10.1111/1753-0407.12428.

20. Wang HH, Wang JJ, Wong SY, Wong MC, Mercer SW, Griffiths SM. The development of urban community health centres for strengthening primary care in China: a systematic literature review. Br Med Bull. 2015;116:139-53.

21. Ncube-Zulu T, Danckwerts MP. Comparative hospitalization cost and length of stay between patients with and without diabetes in a large tertiary hospital in Johannesburg, South Africa. Int J Diab Dev Ctries. 2013;34(3):156-62.

22. He M, Ma J, Wang D, Yu X. Costs for hospitalized patients with diabetes mellitus in China. Asia-Pac J Public Health. 2015;27(2):NP925-35.

23. Kubo T, Fujino Y, Murata A, Ichimiya Y, Kuwabara K, Fujimori K, Horiguchi $H$, Matsuda S. Prevalence of type 2 diabetes among acute inpatients and its impact on length of hospital stay in Japan. Intern Med. 2011;50(5):405-11.

24. Xiong $X$, Lin J, Xiong G. Medical cost and settlement pattern study on diabetes mellitus insurants in China. Value In Health. 2010;13(3):A58.

25. Richard P, Shin P, Beeson T, Burke LS, Wood SF, Rosenbaum S. Quality and cost of diabetes mellitus care in community health centers in the United States. Plos One. 2015;10(12):e0144075.

26. Esteghamati A, Khalilzadeh O, Anvari M, Meysamie A, Abbasi M, Forouzanfar M, Alaeddini F. The economic costs of diabetes: a population-based study in Tehran. Iran Diabetologia. 2009;52(8):1520-7.

27. Li T, Long H, Tu S, Wang Y. Analysis of income inequality based on income mobility for poverty alleviation in rural China. Sustainability. 2015;7(12): 16362-78.

28. Terra SG, Vincent J. Type 2 diabetes: progress made but still a long road to travel to reduce disease burden. Clin Pharmacol Ther. 2015:98(2):108-11.

29. Lee KW. Costs of diabetes mellitus in Korea. Diabetes Metab J. 2011;35(6): $567-70$.

30. Wang W, Fu CW, Pan CY, Chen W, Zhan S, Luan R, Tan A, Liu Z, Xu B. How do type 2 diabetes mellitus-related chronic complications impact direct medical cost in four major cities of urban China? Value Health. 2009;12(6): 923-9.

31. Davies MJ, Gray L, Troughton J, Gray A, Tuomilehto J, Faroogi A, Khunti K, Yates T, Let's Prevent Diabetes T. A community based primary prevention programme for type 2 diabetes integrating identification and lifestyle intervention for prevention: the Let's Prevent Diabetes cluster randomised controlled trial. Prev Med. 2016;84:48-56.

32. Modesti PA, Galanti G, Cala P, Calabrese M. Lifestyle interventions in preventing new type 2 diabetes in Asian populations. Intern Emerg Med. 2016;11(3):375-84.

\section{Submit your next manuscript to BioMed Central and we will help you at every step:}

- We accept pre-submission inquiries

- Our selector tool helps you to find the most relevant journal

- We provide round the clock customer support

- Convenient online submission

- Thorough peer review

- Inclusion in PubMed and all major indexing services

- Maximum visibility for your research

Submit your manuscript at www.biomedcentral.com/submit

Biomed Central 